\title{
Effects of piano training on psychophysiological development of primary school children
}

\author{
(iD) Qianye Li \\ Music and Dance Academy, Guizhou Minzu University, Guiyang, China \\ 644512298@qq.com \\ iD Olga Matvieieva \\ Department of Teacher Musical and Artistic Training, H.S. Skovoroda Kharkiv National \\ Pedagogical University, Kharkiv, Ukraine \\ oamat@ukr.net \\ (iD) Xuanye Wang \\ Music College, Ningbo University, Ningbo, China \\ 547005949@qq.com \\ Yingzhi Wang \\ Department of Preschool Education, Ningbo Childhood Education College, Ningbo, China \\ 732581055@qq.com
}

\begin{abstract}
The aim of this work is to study the supposed influence of piano training on the underlying indicators of psychophysiological development in children aged 7 years $(n=110)$. There were more children with right hand dominance among those who received piano training. It was found that piano players achieved a higher level of maturation of the functional brain structures. Children receiving piano training demonstrated stronger activation of the anterior regions of the brain, whereas children who did not play any musical instrument showed more activation of the right hemisphere and the occipital region in the neocortex.
\end{abstract}

Keywords: Asymmetric movement. Bimanual movement. Piano training. Reciprocal movement. Synkinetic movement. 
Resumo: O objetivo deste trabalho é estudar a suposta influência do treinamento de piano nos indicadores subjacentes do desenvolvimento psicofisiológico em crianças de 7 anos $(n=110)$. Havia mais crianças com domínio da mão direita entre aqueles que receberam treinamento de piano. Verificou-se que os pianistas alcançaram um maior nível de maturação das estruturas cerebrais funcionais. Crianças que receberam treinamento de piano demonstraram ativação mais forte das regiões anteriores do cérebro, enquanto crianças que não tocavam nenhum instrumento musical mostraram mais ativação do hemisfério direito e da região occipital no neocórtex.

Palavras-chave: Movimento assimétrico. Movimento bimanual. Treinamento de piano. Movimento recíproco. Movimento sincinético.

Submetido em: 16 de junho de 2021

Aceito em: 31 de julho de 2021 
Effects of piano training on psychophysiological development of primary school children Qianye Li • Olga Matvieieva · Xuanye Wang • Yingzhi Wang

\section{Introduction}

One of the most valuable and interesting topics in contemporary physiology revolves around the effect of a rhythmic sensory stimulation on the brain in different age groups (AUNE et al., 2020). Particular attention is paid to individuals that experience the active formation of higher mental functions - children. Qualitative and quantitative indicators of sensory flow are predictors of the ontogeny of mental development (HIRANO et al., 2020). Therefore, it seems to be crucial to investigate how the rhythmic sensory stimulation affects child's psychophysiological development. Among divergent types of motor activity, learning to play a musical instrument imposes a specific motor load, which relies on bimanual performance. In other words, playing requires a person to use both hands. The load on a non-dominant hand thus increases. Playing an instrument is somewhat different from playing sports because music training involves a variety of tasks that require a higher level of finger dexterity (HIRANO et al., 2020; TAKEUCHI et al., 2012). The complexity of such tasks increases gradually along with learner's motor skills and bimanual proficiency. In secondary school, learners are exposed to motor activities that affect their dominant hands, such as dictation writing. Playing musical instruments at this age, according to some sources, can have a decisive effect on the morphology and functional development of the central nervous system (SCHOTT and KLOTZBIER, 2018; SPAMPINATO and CELNIK, 2018, 2020).

At age 6 to 7, children are exposed to intense bimanual motor activity and, consequently, the volume of information that travels between the cerebral hemispheres increases. However, the effect of increased motor activity on brain may not be strong due to the relative immaturity of connections between the hemispheres at this age (RICHARDSON, 2011). Playing on musical instruments has the potential to bolster transcallosal connections, accelerating the formation of interhemispheric interaction or interhemispheric assymentry (MAGILL, 2006). The age period from 6 to 7 years is 
Effects of piano training on psychophysiological development of primary school children Qianye Li • Olga Matvieieva • Xuanye Wang • Yingzhi Wang

important for the maturation of the central nervous system because of the structural changes to the frontal region in the neocortex (LORÅS et al., 2012; SWINNEN and GOOIJERS, 2015). Similar processes occur with the network structure of interhemispheric coordination (AUNE et al., 2017). Therefore, intense activities at this age, such as playing a musical instrument, can affect child's brain development.

Today, there is a belief that age does not matter if a person wishes to learn music and that anyone can start from scratch even at older age. Sadly, this does not ring true. According to literature, college students with a musical background perform better in the music class that students who did not play a musical instrument in primary school (HÜBERS et al., 2008; LIUZZI et al., 2011). The education industry is fully aware of the said skills gap. The current music education programs for preschool- and school-age students offer a vast variety of methodologies and techniques that help them to become a better musician in the future. Among other things, such programs aim at the formation and improvement of the pianistic apparatus (HIRANO et al., 2020). Given the effect these programs have on a child, early participation in music training may affect personality development. As educational requirements continue to increase, it seems pertinent to put children in music lessons as early as possible, laying down the foundations for rapid personal growth. The psychophysiological aspects of ontogenesis of the central nervous system serve as support for this conclusion. On the other hand, the introduction of fine motor activities at older age shows no promise, at least in institutions for higher music education (GOOIJERS and SWINNEN, 2014; HESSE et al., 2020). Respondents without a musical background were excluded from the studies (CALVIN et al., 2010). At the same time, more studies to show the role of music training at the age of 7 in developing powerful interhemispheric connections are needed (HIRANO et al., 2020). A deeper presentation requires using an integrated approach to explore how playing a musical instrument affects psychophysiological development in children. 
Effects of piano training on psychophysiological development of primary school children Qianye Li • Olga Matvieieva · Xuanye Wang • Yingzhi Wang

The present work investigates the psychophysiological responsiveness in 7-year-olds who take regular piano lessons. Hypothetically, the piano training has an enhancing effect on interhemispheric connectivity and thus affects the psychophysiological performance. The objectives of the study are: (1) to conduct psychophysiological and sensorimotor testing of children across the experimental and control groups; and (2) to carry out the electroencephalographic examination of children across the control and experimental groups. The observed data serves as a basis for testing the plausibility of a research hypothesis.

\section{Method}

\section{Study Design and Sample}

The study was conducted in Beijing (PRC) in 2019 with the involvement of 110 schoolchildren aged 7 (mean age, $7.5 \pm 0.2$ years). Of these children, 50 were recruited from a music school. Other children were from the same secondary school and did not receive additional music training. All children were divided in two groups: a control group with 60 children having no musical background and an experimental group with 50 children who began learning the piano 6 to 8 months before the study. Half of children in both groups underwent electroencephalogram (EEG) examination.

This study is divided into two parts. The first part involves the sensorimotor and psychophysiological tests. The second part consists of elucidating the bioelectrical activity of the brain at rest and during the bimanual piano performance (EEG recording). All experiments were carried out in the same room with comfortable temperature and lighting conditions.

All children voluntarily agreed to participate in this study, and their parents granted a written approval for their children to 
Effects of piano training on psychophysiological development of primary school children Qianye Li • Olga Matvieieva • Xuanye Wang • Yingzhi Wang

participate. Also, their teachers were notified of their participation. All participants were guaranteed anonymity and confidentiality. All experiments were carried out in accordance with the Declaration of Helsinki and were approved by the Ethics Committee of the Peking University (Protocol No. 32-997). Children enrolled in the study were 7 years old and had none of the following health issues: epilepsy, cardiovascular diseases, and disorders of the nervous system. Children who did not meet these inclusion criteria, or did not agree to participate, or whose parents did not give their consent were excluded from this study.

\section{Experiment}

The each child's dominant hand and asymmetries in hand function were determined by using the Annet Hand Preference Questionnaire (ANNET, 1978). Other functional measures that were addressed during the study are the foot preference in footballrelated behaviors, the ear preference for cell phone conversations or listening to a watch, and the eye preference, as determined by the Rosenbach's sighting test. To identify the eye preferred for sighting, a child was given a pencil and asked to look at a distant object without squinting. The assistant alternately covered the child's right and left eyes. The sighting accuracy determined the eye dominance. The voluntary concentration and level of attention were measured using the Pieron-Ruser test and the Bourdon test, in which multiple signs (pluses, minuses, dots, and spaces) are arranged in a geometric formation, such as a square of a circle. These tests are time-constrained. The Analogy and Odd One Out tests were used to measure progress in thinking. The tactile perception was evaluated with the help of a Seguin form board, a wooden board with different-sized holes in it. Children were asked to fill in these holes with the corresponding geometric objects or their combinations until the board is completed. 
Effects of piano training on psychophysiological development of primary school children Qianye Li • Olga Matvieieva • Xuanye Wang • Yingzhi Wang

Bimanual coordination was assessed during three bimanual tasks requiring mirror-symmetrical or synkinetic, reciprocal, and asymmetric movements of the fingers and hands. The first, mirrorsymmetrical, task consisted of alternately touching fingers two through five with the thumb on both hands simultaneously. The second, reciprocal, test involved getting the child to clench and unclench the fingers on each of the hands resting on the table in a reciprocal fashion. The third, asymmetric, task involved tapping twice with one hand for each single tap by the other hand.

The EEG recording was performed at rest with closed eyes and in response to bimanual piano-like performance. The electrodes were positioned according to the 10/20 electrode placement system at F3, F4, C3, C4, P3, P4, O1, O2, T3, and T4. The recording was carried out in a monopolar mode (ear reference), with a sampling rate of $125 \mathrm{Hertz}(\mathrm{Hz})$. The duration of each epoch was 3 seconds. The recording periods (rest and stimulation) were divided into 20 to 25 epochs of 3 seconds. The resulting EEG data involve the average frequency and the spectral power density in every frequency band. The ranges were taken from 3 standard (i, b, c). The delta frequency band was excluded from the analysis due to a high risk of movement artifacts.

\section{Statistical Analysis}

The data collected were stored in Microsoft Excel 2016 (Microsoft Corp., USA). Additional statistical processing was carried out by Statistica v. 7.0 (StatSoft Inc, USA). The tables present arithmetic means for each and standard errors of the mean. The intergroup differences were compared using the Student's t-test or Multivariate ANOVA (MANOVA). The Pearson's correlation was used to establish the strength of the relationship between variables. The statistical differences were considered significant at $p \leq 0.05$. 
Effects of piano training on psychophysiological development of primary school children Qianye Li • Olga Matvieieva • Xuanye Wang • Yingzhi Wang

\section{Results}

The hand preference analysis showed that all participants were right-handed with a right hand dominance of 15 to 25 points. There were no significant differences found between groups as determined by functional asymmetry assessment. At the same time, there were more children with a dominant right hand in the experimental group ( 16 children vs 9 children, $p \leq 0.05$ ).

During the cognitive tests, children in both groups showed stronger synthesis skills and weaker analysis skills. Also, children who played piano outperformed those who did not play any musical instrument on every task. According to the results of bimanual tests, the experimental group is ahead of the control group in coordinating the movements of both hands. Although, both groups demonstrated a high level of performance on synkinetic task (46 children out of 50 in the experimental group and 46 children out of 60 in the control group completed the task successfully), children playing a piano performed better on reciprocal ( 25 children vs 16 children) and asymmetric ( 27 children vs 19 children) tasks $(p \leq 0.01)$. There was no relationship detected between the degree of functional interhemispheric asymmetry and bimanual performance.

The EEG data analysis revealed higher power in alpha ( $p \leq$ $0.05)$ and beta $(p \leq 0.01)$ frequencies. In addition, it was found that children playing a piano experienced a shift in alpha and beta activity in the left hemisphere (Table 1). 
Effects of piano training on psychophysiological development of primary school children Qianye Li • Olga Matvieieva • Xuanye Wang • Yingzhi Wang

Table 1 - Spectral EEG characteristics of children in the experimental group at rest and during bimanual piano-like performance

\begin{tabular}{|c|c|c|c|c|c|c|c|c|}
\hline \multirow{2}{*}{$\begin{array}{l}\text { Rhythm } \\
\text { Parameter }\end{array}$} & \multicolumn{2}{|l|}{ Alpha } & \multicolumn{2}{|l|}{ Beta } & \multicolumn{2}{|l|}{ Alpha } & \multicolumn{2}{|l|}{ Beta } \\
\hline & $\begin{array}{l}\text { Rhythm } \\
\text { power }\end{array}$ & $\begin{array}{l}\text { Frequency } \\
\text { (average) }\end{array}$ & $\begin{array}{l}\text { Rhythm } \\
\text { power }\end{array}$ & $\begin{array}{l}\text { Frequency } \\
\text { (average) }\end{array}$ & $\begin{array}{l}\text { Rhythm } \\
\text { power }\end{array}$ & $\begin{array}{l}\text { Frequency } \\
\text { (average) }\end{array}$ & $\begin{array}{l}\text { Rhythm } \\
\text { power }\end{array}$ & $\begin{array}{l}\text { Frequency } \\
\text { (average) }\end{array}$ \\
\hline \multirow{2}{*}{$\begin{array}{l}\text { Condition } \\
\text { pair }\end{array}$} & \multicolumn{8}{|c|}{ t-statistic } \\
\hline & \multicolumn{4}{|c|}{ Channel F3 } & \multicolumn{4}{|c|}{ Channel F4 } \\
\hline $1-2$ & 0.05 & 0.41 & 0.07 & 0.36 & 0.13 & 0.43 & 0.33 & 0.21 \\
\hline \multirow[t]{2}{*}{$1-3$} & 0.03 & 0.49 & 0.08 & 0.16 & 0.07 & 0.40 & 0.28 & 0.17 \\
\hline & \multicolumn{4}{|c|}{ Channel T3 } & \multicolumn{4}{|c|}{ Channel T4 } \\
\hline \multirow[t]{2}{*}{$1-4$} & 0.39 & 0.032 & 0.24 & 0.35 & 0.51 & 0.02 & 0.51 & 0.42 \\
\hline & \multicolumn{4}{|c|}{ Channel C3 } & \multicolumn{4}{|c|}{ Channel C4 } \\
\hline $1-4$ & 0.17 & 0.15 & 0.01 & 0.37 & 0.32 & 0.11 & 0.05 & 0.40 \\
\hline $1-2$ & 0.04 & 0.01 & 0.17 & & & & & \\
\hline \multirow[t]{2}{*}{$1-3$} & 0.02 & 0.03 & 0.47 & 0.15 & 0.36 & 0.15 & 0.47 & \\
\hline & \multicolumn{4}{|c|}{ Channel P3 } & \multicolumn{4}{|c|}{ Channel P4 } \\
\hline \multirow[t]{2}{*}{$1-4$} & 0.39 & 0.21 & 0.027 & 0.39 & 0.31 & 0.10 & 0.51 & 0.17 \\
\hline & \multicolumn{4}{|c|}{ Channel 01} & \multicolumn{4}{|c|}{ Channel $\mathrm{O} 2$} \\
\hline $1-4$ & 0.25 & 0.24 & 0.001 & 0.43 & 0.41 & 0.32 & 0.07 & 0.18 \\
\hline $1-2$ & 0.29 & 0.31 & 0.001 & 0.46 & 0.30 & 0.33 & 0.14 & 0.35 \\
\hline $1-3$ & 0.29 & 0.23 & 0.001 & 0.39 & 0.31 & 0.19 & 0.08 & 0.29 \\
\hline
\end{tabular}

Note: Conditions: 1 - rest with closed eyes, 2 - reciprocal movement, 3 - asymmetric movement, 4 - synkinetic movement. Statistical differences are marked in bold.

In the control group, statistical differences were mostly seen among the frequencies of theta rhythm (Table 2). 
Effects of piano training on psychophysiological development of primary school children Qianye Li • Olga Matvieieva • Xuanye Wang • Yingzhi Wang

Table 2 - Spectral EEG characteristics of children in the control group at rest and during bimanual piano-like performance.

\begin{tabular}{|c|c|c|c|c|c|c|c|c|c|c|c|c|c|}
\hline 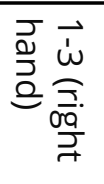 & $\overrightarrow{\dot{N}}$ & & 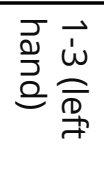 & & 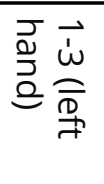 & 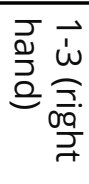 & & 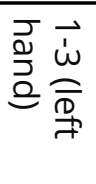 & 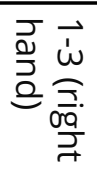 & & 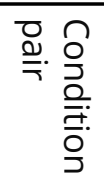 & 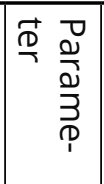 & 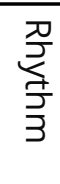 \\
\hline $\begin{array}{l}\stackrel{\circ}{\text { N }} \\
\text { un }\end{array}$ & iu & \multirow{8}{*}{ 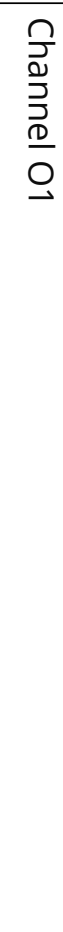 } & $\begin{array}{l}\text { 우 } \\
\text { 으 }\end{array}$ & \multirow{8}{*}{ 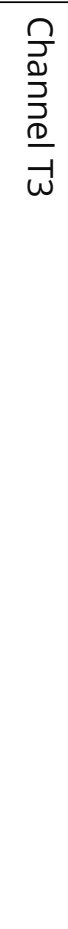 } & $\stackrel{\circ}{\circ}$ & $\stackrel{\circ}{\vec{\omega}}$ & \multirow{8}{*}{ 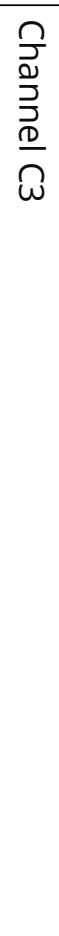 } & $\begin{array}{l}\circ \\
\dot{b}\end{array}$ & $\begin{array}{l}\stackrel{\circ}{N} \\
\stackrel{\Delta}{n}\end{array}$ & \multirow{8}{*}{ 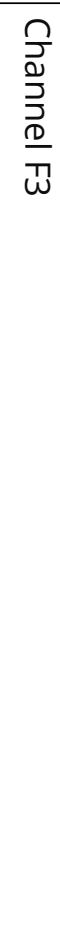 } & \multirow{8}{*}{ 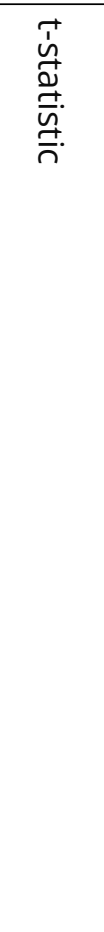 } & - & \multirow[t]{2}{*}{$\begin{array}{l}\vec{D} \\
\frac{D}{D} \\
\end{array}$} \\
\hline in & $\stackrel{\circ}{\vec{\ominus}}$ & & $\stackrel{\circ}{\circ}$ & & 웅 & $\stackrel{\circ}{\vec{v}}$ & & $\begin{array}{l}\circ \\
\text { के }\end{array}$ & $\stackrel{\circ}{\vec{v}}$ & & & $\pi$ & \\
\hline$\stackrel{\circ}{\stackrel{\sim}{\Lambda}}$ & $\stackrel{\circ}{\omega}$ & & $\stackrel{\circ}{\stackrel{\perp}{\perp}}$ & & & & & $\stackrel{\circ}{\underset{\omega}{u}}$ & $\stackrel{\circ}{\stackrel{\sim}{N}}$ & & & - & \multirow[t]{2}{*}{ 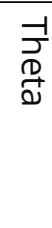 } \\
\hline$\stackrel{\circ}{\circ}$ & $\stackrel{\stackrel{\sim}{\sim}}{ }$ & & Oे & & Oे & $\stackrel{\circ}{\vec{\omega}}$ & & نे & $\stackrel{\stackrel{\sim}{\Delta}}{\stackrel{D}{n}}$ & & & $\pi$ & \\
\hline$\stackrel{\circ}{\dot{\sigma}}$ & $\stackrel{\circ}{\stackrel{O}{\Lambda}}$ & & $\begin{array}{l}\text { Oे } \\
\text { N }\end{array}$ & & 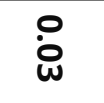 & $\stackrel{\circ}{\vec{\Delta}}$ & & & ir & & & - & \multirow[t]{2}{*}{ 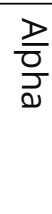 } \\
\hline$\stackrel{\circ}{\vec{v}}$ & $\stackrel{\circ}{\dot{w}}$ & & $\stackrel{\circ}{\vec{v}}$ & & & & & $\stackrel{\circ}{\vec{v}}$ & $\begin{array}{l}\circ \\
\text { मे }\end{array}$ & & & $\pi$ & \\
\hline $\begin{array}{l}\stackrel{0}{U} \\
\text { On }\end{array}$ & $\stackrel{\circ}{\overrightarrow{0}}$ & & $\stackrel{\circ}{i}$ & & $\stackrel{\circ}{\stackrel{N}{N}}$ & $\stackrel{\circ}{\stackrel{\sim}{u}}$ & & $\stackrel{\circ}{\stackrel{N}{V}}$ & $\stackrel{\circ}{\underset{\infty}{\infty}}$ & & & - & \multirow[t]{2}{*}{$\begin{array}{l}\text { W } \\
\mathbb{D} \\
\mathbb{Q}\end{array}$} \\
\hline $\begin{array}{l}\stackrel{\circ}{\sim} \\
\text { O }\end{array}$ & $\begin{array}{l}\stackrel{\circ}{\vec{D}} \\
\end{array}$ & & $\underset{\sim}{\stackrel{O}{u}}$ & & $\stackrel{\stackrel{\circ}{\omega}}{\vec{\omega}}$ & $\stackrel{\circ}{\stackrel{\circ}{\omega}}$ & & $\stackrel{\text { }}{\sim}$ & $\begin{array}{l}\stackrel{\circ}{N} \\
\stackrel{N}{n}\end{array}$ & & & $\pi$ & \\
\hline & in & \multirow{8}{*}{ 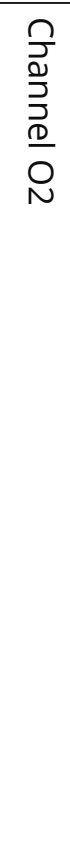 } & $\stackrel{\circ}{\vec{v}}$ & \multirow{8}{*}{$\begin{array}{l}\frac{0}{2} \\
\frac{0}{3} \\
\frac{3}{0} \\
\frac{1}{D}\end{array}$} & $\begin{array}{l}\circ \\
\infty\end{array}$ & $\stackrel{\circ}{\dot{\omega}}$ & \multirow{8}{*}{ 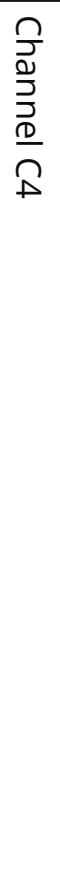 } & $\stackrel{\circ}{\dot{\omega}}$ & $\begin{array}{l}\circ \\
\text { मे }\end{array}$ & \multirow{8}{*}{\multicolumn{2}{|c|}{ 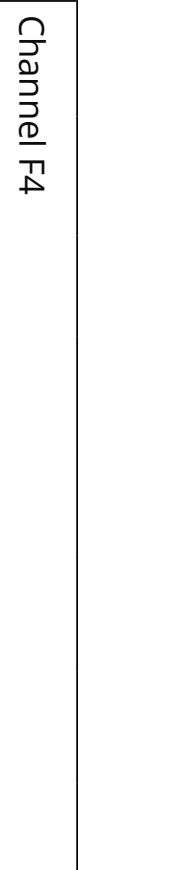 }} & - & \multirow[t]{2}{*}{$\begin{array}{l}\underset{D}{D} \\
\frac{D}{\Phi}\end{array}$} \\
\hline ì & $\dot{\mathrm{w}}_{\sim}$ & & $\stackrel{\circ}{\dot{w}}$ & & $\begin{array}{l}\stackrel{\circ}{\sigma} \\
\end{array}$ & $\stackrel{\circ}{\circ}$ & & $\stackrel{\stackrel{o}{w}}{\omega}$ & 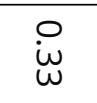 & & & $\pi$ & \\
\hline$\stackrel{\circ}{\omega}$ & O̊ & & $\begin{array}{l}\circ \\
\stackrel{0}{0}\end{array}$ & & $\begin{array}{l}\stackrel{\circ}{N} \\
\stackrel{A}{N}\end{array}$ & $\stackrel{\circ}{\omega}$ & & $\stackrel{\circ}{\sim}$ & $\begin{array}{l}\stackrel{\circ}{\vec{\sigma}} \\
\end{array}$ & & & - & \multirow[t]{2}{*}{$\begin{array}{l}\text { ᄀ' } \\
\stackrel{d}{d} \\
d\end{array}$} \\
\hline 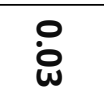 & $\stackrel{\dot{w}}{\circ}$ & & $\begin{array}{l}0 \\
\infty \\
\infty\end{array}$ & & 잉 & 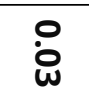 & & ب0 & o & & & $\pi$ & \\
\hline $\begin{array}{l}\stackrel{0}{\sim} \\
\text { o }\end{array}$ & $\stackrel{\circ}{\underset{\omega}{\omega}}$ & & $\stackrel{\circ}{\text { N }}$ & & : & $\stackrel{\circ}{\vec{D}}$ & & & $\begin{array}{l}\stackrel{\circ}{\grave{\omega}} \\
\stackrel{b}{ }\end{array}$ & & & - & \multirow[t]{2}{*}{$\frac{\frac{D}{a}}{\frac{\partial}{\partial}}$} \\
\hline$\stackrel{\circ}{\text { N }}$ & $\begin{array}{l}\circ \\
\text { ○े }\end{array}$ & & $\stackrel{\circ}{\dot{w}}$ & & & $\stackrel{\circ}{\omega}$ & & $\stackrel{\stackrel{O}{\sim}}{a}$ & $\begin{array}{l}\stackrel{\circ}{\text { N }} \\
\text {. }\end{array}$ & & & $\pi$ & \\
\hline $\begin{array}{l}\stackrel{0}{0} \\
\stackrel{0}{0}\end{array}$ & $\stackrel{\circ}{\vec{\theta}}$ & & $\stackrel{\circ}{\text { N }}$ & & 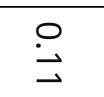 & 우 & & & & & & - & \multirow[t]{2}{*}{$\begin{array}{l}\text { W } \\
\mathbb{D} \\
\mathbb{Q}\end{array}$} \\
\hline $\begin{array}{l}\stackrel{\circ}{v} \\
\vec{v}\end{array}$ & $\stackrel{\circ}{\stackrel{\sim}{\Lambda}}$ & & & & & $\stackrel{\underset{\sim}{\sim}}{\perp}$ & & & $\stackrel{\circ}{\stackrel{\ominus}{V}}$ & & & $\pi$ & \\
\hline
\end{tabular}


Effects of piano training on psychophysiological development of primary school children Qianye Li • Olga Matvieieva • Xuanye Wang • Yingzhi Wang

It was found that bimanual synkinetic movements stimulated the temporal cortices of both hemispheres. Either of the examined bimanual movements provoked the activation of the central and occipital leads in the left hemisphere. At the same time, reciprocal and asymmetric bimanual movements caused the activation of the frontal lobe in the left hemisphere.

During the reciprocal and asymmetric tasks, children in the experimental group showed a decrease in the frequency of theta rhythm. When performing the task requiring complex finger movements, children playing a piano experienced a beta rhythm increase in the right central lead (Figure 1B), while non-playing children demonstrated a reduction of alpha rhythm (Figure 1A). This finding suggests that the performance of bimanual synkinetic movements directly depends on the degree of activation of the right central region.

Figure 1 - Correlation between EEG measures (power and frequency) and bimanual performance in experimental (1A) and control (1B) groups. Pearson's correlation coefficients are given as numbers; dots represent frequency correlations and squares represent power correlations. White color indicates positive correlation whereas grey color indicates negative correlation.

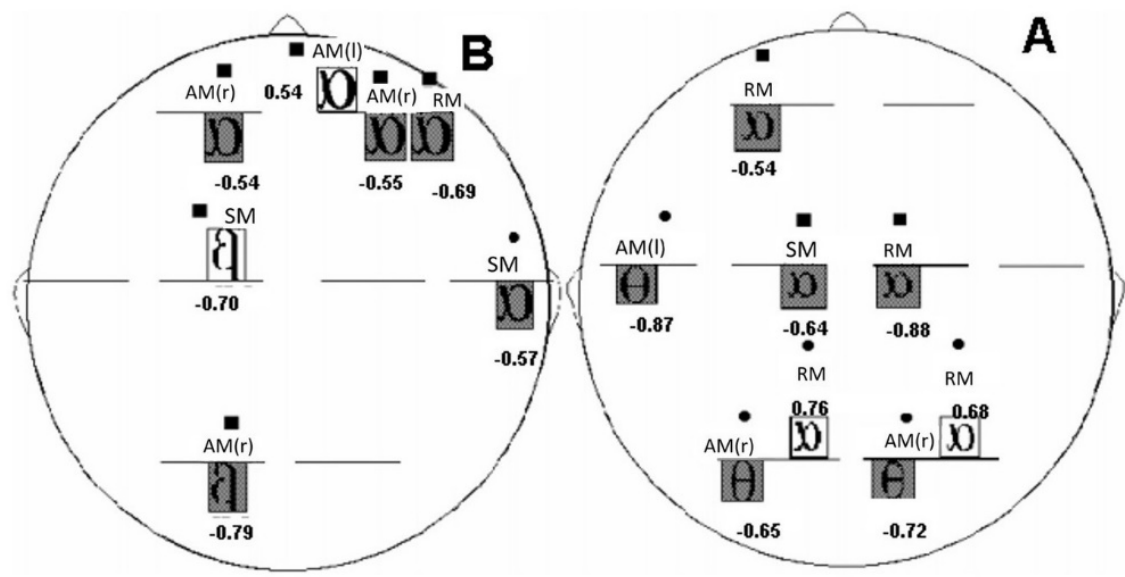

A positive correlation was found in the control group between bimanual reciprocal performance and alpha rhythm decrease in the left central and right frontal regions (Figure 1A). An increase in the alpha rhythm correlated with higher activity in the occipital leads. 
Effects of piano training on psychophysiological development of primary school children Qianye Li • Olga Matvieieva • Xuanye Wang • Yingzhi Wang

Bittern bimanual skills in the experimental group, as determined by asymmetric and reciprocal tasks, are associated with an increased activity in the frontal region of the left hemisphere (Figure 1B). Bimanual asymmetric movements in the control are positively associated with a theta rhythm decrease in the occipital region in both hemispheres of the brain.

From data in Figure 1, piano lessons require the activation of the anterior regions of the brain. Without piano training, increased activation can be seen in the occipital zones of the neocortex, as well as the right hemisphere. The present results indicate that children playing a piano achieved a higher degree of maturation of EEG parameters and more pronounced mechanisms of EEG activity change than children who were not exposed to musical instruments.

\section{Discussion}

Data obtained on the performance of bimanual movements align with the already known facts that an individual forms the ability to coordinate reciprocal movements at the late stage of ontogenesis (SPAMPINATO et al., 2019; STEELE and PENHUNE, 2010). This is due to the rather late development of the corpus callosum, which grows up the age of 24 years, and the frontal neocortex, which reaches maturation at the age of 7 (SPAMPINATO et al., 2017; SPAMPINATO et al., 2019; SPAMPINATO et al., 2020). At the same time, the bimanual synkinetic movements, which 7-yearolds in both groups performed with a high level of success, involved the activation of non-crossed sensory pathways.

We assume that the absence of alterations in the alpha and beta rhythms in the control group during the performance of bimanual reciprocal and synkinetic tasks is due to the dominance of the right hemisphere of the brain in the regulation of voluntary activity. The right hemisphere is known to be less interconnected within 
Effects of piano training on psychophysiological development of primary school children Qianye Li • Olga Matvieieva · Xuanye Wang • Yingzhi Wang

itself, and with the subcortical nuclei, than the left hemisphere (KRAKAUER and MAZZONI, 2011). Therefore, the right hemisphere is characterized by diffuse activation. The comparison of brain activity at rest with eyes closed and in response to bimanual asymmetric movements revealed the existence of small but unidirectional changes to the EEG amplitude of the hemisphere.

The literature shows that the age-related dynamics of child's development by the age of 7 is characterized by an increased involvement of the left hemisphere in the regulation of motor activity, including bimanual movements (JAYARAM et al., 2011; $\mathrm{KOCH}$ et al., 2019, 2020). From this perspective, the identified shifts in EEG activity during the complex bimanual movements may indicate increased brain activity in children playing a piano.

In the control group, bimanual performance largely relied on the activation of the right hemisphere and the occipital zones in the neocortex, whereas children who regularly played a piano relied more on the anterior regions of the brain. Hence, with higher complexity and intensity of the motor load (bimanual movements in three modes), children in the experimental group experienced a change in the strategy of movement coordination, from visual coordination to coordination associated with higher associative structures of the brain. At the same time, the effectiveness of this coordination has steadily increased. It appears that in addition to brain activity shifts, children in the experimental group also had increased EEG background activity. Moreover, these children demonstrated more advanced thinking skills than children in the control group.

The differences between children-musicians and nonmusicians may stem from the fact that children who receive musical training operate in a more saturated sensory environment that those who are not engaged in musical activity. At the same time, children who play a musical instrument are exposed to two different types of stimulation at once: auditory and proprioceptive. Note that at the beginning of piano lessons, the boosting effect can be situational and short-lasting. Finally, the level of music 
Effects of piano training on psychophysiological development of primary school children Qianye Li • Olga Matvieieva · Xuanye Wang • Yingzhi Wang

performance ability is also important because the sounds that a child makes when learning a piano are significantly different from those that come from the same piano when played by a professional musician. Therefore, the auditory stimulation during play may not correspond to that described in the literature when the performer is a non-professional or a child (JAYARAM et al., 2012; KARABANOV et al., 2015). In this light, the results obtained in this study can be considered as a consequence of increased motor activity.

Being associated with innervation of the central nervous system, bimanual motor activity is of particular importance for brain development and maturation in childhood (GALEA et al., 2011; GENTNER et al., 2010). It is able to influence the brain tonus, facilitating the development process. Therefore, bimanual activity in early ontogenesis may be a contributing factor to brain development. At the same time, the irradiation of motor activity directed from the hand stimulates the frontal areas of the cerebral cortex. Of course, this plays an important role in the development of higher mental function, in particular attention and thinking.

\section{Conclusions}

It was found that regular piano lessons at the age of 7 improves the coordination of bimanual reciprocal and asymmetric movements, while exhibiting no substantial effect on synkinetic movement coordination. At the same time, regular piano lessons help to strengthen the right-lateral profile and the left hemisphere. Children who were learning the piano showed higher alpha and beta power than children who did not receive piano training. This finding suggest a higher level of maturation of the functional brain structures in the experimental group. Dynamic re-configurations of EEG brain activity in the experimental group during physical stimulation involved statistically significant changes in alpha and beta rhythms. In addition to that, children in the experimental group experienced the activation of the left hemisphere group 
Effects of piano training on psychophysiological development of primary school children Qianye Li • Olga Matvieieva • Xuanye Wang • Yingzhi Wang

during the performance of complex bimanual movements whereas children in the control group demonstrated the activation of both hemispheres. Bimanual synkinetic performance in both groups was found to be correlating with the degree of activation of the right sensorimotor area of the brain. Finally, during the performance of bimanual reciprocal and asymmetric movements, the experimental group showed more activation of the frontal regions and the control group showed more activation of the occipital regions.

\section{References}

ANNET, Marian. A single gene explanation of brainedness and handedness. Neuroscience Letters, v. 1, p. 253, 1978.

AUNE, Morten Andreas; LORÅS, Håvard; DJUVSLAND, Ane; INGVALDSEN, Rolf Petter; AUNE, Tore Kristian. More pronounced bimanual interference in proximal compared to distal effectors of the upper extremities. Frontiers in Psychology, vol. 11, p. 544990, 2020.

AUNE, Tore K.; AUNE, Morten A.; INGVALDSEN, Rolf P.; VEREIJKEN, Beatrix. Transfer of motor learning is more pronounced in proximal compared to distal effectors in upper extremities. Frontiers in Psychology, vol. 8, p. 1530, 2017.

CALVIN, Sarah; HUYS, Raoul; JIRSA, Viktor K. Interference effects in bimanual coordination are independent of movement type. Journal of Experimental Psychology: Human Perception and Performance, vol. 36, n. 6, p. 1553-1564, 2010.

GALEA, Joseph M.; VAZQUEZ, Alejandro; PASRICHA, Neel; DE XIVRY, JeanJacques Orban; CELNIK, Pablo. Dissociating the roles of the cerebellum and motor cortex during adaptive learning: The motor cortex retains what the cerebellum learns. Cerebral Cortex, vol. 21, n. 8, p. 17611770, 2011.

GENTNER, Reinhard; GORGES, Susanne; WEISE, David; AUFM KAMPE, Kristin; BUTTMANN, Mathias; CLASSEN, Joseph. Encoding of motor skill 
Effects of piano training on psychophysiological development of primary school children Qianye Li • Olga Matvieieva • Xuanye Wang • Yingzhi Wang

in the corticomuscular system of musicians. Current Biology, vol. 20, n. 20, p. 1869-1874, 2010.

GOOIJERS, Jolien; SWINNEN, Stephan P. Interactions between brain structure and behavior: The corpus callosum and bimanual coordination. Neuroscience \& Biobehavioral Reviews, vol. 43, p. 1-19, 2014. HESSE, Constanze; KOROKNAI, Laura; BILLINO, Jutta. Individual differences in processing resources modulate bimanual interference in pointing. Psychological Research, vol. 84, n. 2, p. 440-453, 2020.

HIRANO, Masato; KIMOTO, Yudai; FURUYA, Shinichi. Specialized somatosensory-Motor Integration functions in musicians. Cerebral Cortex, vol. 30, n. 3, p. 1148-1158, 2020.

HÜBERS, Annemarie; OREKHOV, Yuriy; ZIEMANN, Ulf. Interhemispheric motor inhibition: Its role in controlling electromyographic mirror activity. European Journal of Neuroscience, vol. 28, n. 2, p. 364-371, 2008.

JAYARAM, Gowri; GALEA, Joseph M.; BASTIAN, Amy J.; CELNIK, Pablo. Human locomotor adaptive learning is proportional to depression of cerebellar excitability. Cerebral Cortex, vol. 21, n. 8, p. 1901-1909, 2011.

JAYARAM, Gowri; TANG, Byron; PALLEGADDA, Rani; VASUDEVAN, Erin V.L.; Celnik, Pablo; BASTIAN, Amy. Modulating locomotor adaptation with cerebellar stimulation. Journal of Neurophysiology, vol. 107, n. 11, p. 2950-2957, 2012.

KARABANOV, Anke; ZIEMANN, UIf; HAMADA, Masashi; MASSIMINI, Marcello; ROTHWELL, John; SIEBNER, Hartwig Roman. Consensus paper: Probing homeostatic plasticity of human cortex with non-invasive Iranscranial Prain stimulation. Brain Stimulation, vol. 8, n. 5, p. 9931006, 2015.

KOCH, Giacomo; BONNÌ, Sonia; CASULA, Elias Paolo; IOSA, Marco; PAOLUCCI, Stefano; PELLICCIARI, Maria Concetta; CINNERA, Alex Martino, et al. Effect of cerebellar stimulation on gait and balance recovery in patients with hemiparetic stroke: A randomized clinical trial. JAMA Neurology, vol. 76, n. 2, p. 170-178, 2019. 
Effects of piano training on psychophysiological development of primary school children Qianye Li • Olga Matvieieva • Xuanye Wang • Yingzhi Wang

KOCH, Giacomo; ESPOSITO, Romina; MOTTA, Caterina; CASULA, Elias Paolo; DI LORENZO, Francesco; BONNì, Sonia; CINNERA, Alex Martino, et al. Improving visuo-motor learning with cerebellar theta burst stimulation: behavioral and neurophysiological evidence. Neuroimage, vol. 208, p. 116424, 2020.

KRAKAUER, John W.; MAZZONI, Pietro. Human sensorimotor learning: Adaptation, skill, and beyond. Current Opinion in Neurobiology, vol. 21, n. 4, p. 636-644, 2011.

LIUZZI, Gianpiero; HÖRNIß, Vanessa; ZIMERMAN, Maximo; GERLOFF, Christian; HUMMEL, Friedhelm C. Coordination of uncoupled bimanual movements by strictly timed interhemispheric connectivity. Journal of Neuroscience, vol. 31, n. 25, p. 9111-9117, 2011.

LORÅS, Håvard; SIGMUNDSSON, Hermundur; TALCOTT, Joel B.; ÖHBERG, Fredrik; STENSDOTTER, Ann-Katrin. Timing continuous or discontinuous movements across effectors specified by different pacing modalities and intervals. Experimental Brain Research, vol. 220, n. 3-4, p. 335-347, 2012.

MAGILL, Richard A. Motor Learning and Control: Concepts and Applications with PowerWeb and OLC. New York: McGraw-Hill, 2006.

RICHARDSON, John T.E. Eta squared and partial eta squared as measures of effect size in educational research. Educational Research Review, vol. 6, n. 2, p. 135-147, 2011.

SCHOTT, Nadja; KLOTZBIER, Thomas J. Profiles of cognitive-motor interference during walking in children: Does the motor or the cognitive task matter? Frontiers in Psychology, vol. 9, p. 947, 2018.

SPAMPINATO, Danny A.; CELNIK, Pablo A.; ROTHWELL; John C. Cerebellar-motor cortex connectivity: One or two different networks? Journal of Neuroscience, vol. 40, n. 21, p. 4230-4239, 2020. SPAMPINATO, Danny A.; SATAR, Zabina; ROTHWELL, John C. Combining reward and $\mathrm{M} 1$ transcranial direct current stimulation enhances the retention of newly learnt sensorimotor mappings. Brain Stimulation, vol. 12, n. 5, p. 1205-1212, 2019. 
Effects of piano training on psychophysiological development of primary school children Qianye Li • Olga Matvieieva · Xuanye Wang • Yingzhi Wang

SPAMPINATO, Danny; BLOCK, Hannah; CELNIK, Pablo A. Cerebellar-M1 connectivity changes associated with motor learning are somatotopic specific. Journal of Neuroscience, vol. 37, n. 9, p. 2377-2386, 2017. SPAMPINATO, Danny; CELNIK, Pablo. Deconstructing skill learning and its physiological mechanisms. Cortex, vol. 104, p. 90-102, 2018. SPAMPINATO, Danny; CELNIK, Pablo. Multiple motor learning processes in humans: Defining their neurophysiological bases. The Neuroscientist, vol. 27, n. 3, p. 246-267, 2020.

STEELE, Christopher J.; PENHUNE, Virginia B. Specific increases within global decreases: A functional magnetic resonance imaging investigation of five days of motor sequence learning. Journal of Neuroscience, vol. 30, n. 24, p. 8332-8341, 2010.

SWINNEN, Stephan P.; GOOIJERS, Jolien. Bimanual coordination. Brain Mapping: An Encyclopedic Reference, vol. 2, p. 475-482, 2015.

TAKEUCHI, Naoyuki; OOUCHIDA, Yutaka; IZUMI, Shin-Ichi. Motor control and neural plasticity through interhemispheric interactions. Neural Plasticity, vol. 2012, p. 823285, 2012.

\section{Research ethics committee approval}

All experiments were carried out in accordance with the Declaration of Helsinki and were approved by the Ethics Committee of the Peking University (Protocol No. 32-997).

\section{Publisher}

Federal University of Goiás. School of Music and Performing Arts. Graduate Program in Music. Publication in the Portal of Periodicals UFG.

The ideas expressed in this article are the responsibility of their authors, and do not necessarily represent the opinion of the editors or the university. 